\title{
The hsa-miR-181a-5p reduces oxidation resistance by controlling SECISBP2 in osteoarthritis
}

\author{
Jianli Xue ${ }^{1}$, Zixin Min², Zhuqing Xia ${ }^{3}$, Bin Cheng ${ }^{1}$, Binshang Lan', Fujun Zhang ${ }^{2}$, Yan Han², Kunzheng Wang ${ }^{1 *}$ \\ and Jian Sun ${ }^{2}$
}

\begin{abstract}
Background: The phenotypes of osteoarthritis (OA) consist of cartilage extracellular matrix (ECM) metabolism disorder and the breakdown of cartilage homeostasis, which are induced by pro-inflammatory factors and oxidative stress. Selenoproteins regulated by selenocysteine insertion sequence binding protein 2 (SBP2) are highly effective antioxidants, but their regulatory mechanisms, particularly the involvement of miRNAs, are not fully understood.

Methods: To explore whether miR-181a-5p and SBP2 are involved in OA pathogenesis, we established an IL-1 $\beta$ model using the chondrocyte SW1353 cell line. Next, we up- or down-regulated SBP2 and miRNA-181a-5p expression in the cells. Finally, we measured the expression of miRNA-181a-5p, SBP2 and three selenoproteins in OA cartilage and peripheral blood.

Results: The results showed that IL-1 $\beta$ increased hsa-miR-181a-5p and decreased SBP2 in a time- and dose-dependent manner. GPX1 and GPX4, which encode crucial glutathione peroxidase antioxidant enzymes, were up-regulated along with SBP2 and miR-181a-5p. Furthermore, SBP2 showed a significant negative correlation with miR-181a-5p during induced ATDC5 cell differentiation. There was lower GPX1 and GPX4 mRNA expression and SBP2 protein expression in damaged cartilage than in smooth cartilage from the same OA sample, and hsa-miR-181a-5p expression on the contrary. Similar results were observed in peripheral blood. In conclusion, we have reported a novel pathway in which pro-inflammatory factors, miRNA, SBP2 and selenoproteins are associated with oxidation resistance in cartilage.

Conclusion: Overall, this study provides the first comprehensive evidence that pro-inflammatory factors cause changes in the cartilage antioxidant network and describes the discovery of novel mediators of cartilage oxidative stress and OA pathophysiology. Our data suggest that miR-181a-5p may be used to develop novel early-stage diagnostic and therapeutic strategies for OA.
\end{abstract}

Keywords: miRNA-181a-5p, SECISBP2, Selenoprotein, Cartilage, Osteoarthritis

\section{Background}

Osteoarthritis (OA) may be a response to superfluous mechanical stress or inflammation, and pro-inflammatory factors, including interleukin-1 (IL-1 $\beta)$, interleukin-6 (IL-6), and tumour necrosis factor- $\alpha$ (TNF- $\alpha$ ), are involved in OA pathogenesis $[1,2]$. The phenotypes of cartilage injury processes induced by pro-inflammatory factors are

\footnotetext{
* Correspondence: wkzh1955@163.com

1Department of Orthopaedics, The Second Affiliated Hospital, Xi'an Jiaotong University Health Science Center, 157 West 5th Road, Xi'an, Shaanxi 710004 People's Republic of China

Full list of author information is available at the end of the article
}

cartilage extracellular matrix (ECM) metabolic disorder, the disruption of cartilage homeostasis, and enhanced expression of matrix degradation enzymes such as MMP13 [3]. MMP13, a major enzyme hydrolysing type-II collagen (COL2), is a dominant protein component of the cartilage ECM $[4,5]$ and a biomarker for arthritis progression and therapeutic effects [6-8].

Reactive oxygen species (ROS) are products of aerobic metabolism that injure DNA, proteins, and cellular membranes [9-11]. Oxidative stress plays important roles in the pathogenesis of OA and cartilage degradation, which is induced by ROS, and traumatic loading

(c) The Author(s). 2018 Open Access This article is distributed under the terms of the Creative Commons Attribution 4.0 International License (http://creativecommons.org/licenses/by/4.0/), which permits unrestricted use, distribution, and reproduction in any medium, provided you give appropriate credit to the original author(s) and the source, provide a link to the Creative Commons license, and indicate if changes were made. The Creative Commons Public Domain Dedication waiver (http://creativecommons.org/publicdomain/zero/1.0/) applies to the data made available in this article, unless otherwise stated. 
increases cartilage oxidation and causes cell death [12]. In addition, oxidative stress-mediated regulation of the expression of redox-sensitive proteins is regarded as a key mechanism underlying age-related cellular dysfunction and disease progression [13].

Selenoproteins (Sel) are important members of a network of antioxidant enzymatic systems and minimize damage induced by ROS. They contain selenocysteine (Sec), the 21st proteinogenic amino acid, which is named after the essential biological trace element selenium (Se) and acts as an active-site residue essential for the catalytic activity of selenoproteins [9-11]. The genetic code 'UGA', commonly a termination codon in cells, encodes Sec into selenoproteins [14]. Several special cis-trans elements and trans-acting factors, typically the Sec insertion sequence (SECIS) and Sec insertion sequence binding protein 2 (SECISBP2 or SBP2), regulate selenoprotein biosynthesis $[15,16]$. SECIS, which is located in the selenoprotein mRNA 3 '-untranslated region (3'-UTR), binds with SBP2. The function of SBP2 is to carry Sec-tRNA ${ }^{\text {Sec }}$ into the ribosome 'A site' to recognize 'UGA' as the Sec codon during selenoprotein synthesis $[15,16]$.

Intriguingly, osteo-chondroprogenitor-specific deletion of the selenocysteinyl tRNA ${ }^{\text {Sec }}$ gene results in dyschondroplasia phenotypes, particularly those showing abnormal skeletal development in mice [17]. 'UGA' is recognized as a termination codon, and inactive truncated selenoproteins are produced in the presence of insufficient Sec-tRNA ${ }^{\text {Sec }}$ [18]. Similarly, the TrxR1 short inactive fragment, a two-amino-acid truncated C-terminal motif, leads to the death of human lung carcinoma A549 cells [19]. However, little is known about how selenoprotein biosynthesis regulates OA cartilage. In particular, the pathway from pro-inflammatory factors to selenoprotein biosynthesis mediated by SBP2 in cartilage is poorly understood.

Moreover, more than 20 miRNAs, such as the cartilage-specific miR-140-5p, participate in chondrogenesis, cartilage homeostasis and degradation, and chondrocyte metabolism, which are closely associated with OA development [20-22]. Further, miR-9, miR-34a and miR-146a are related with oxidative stress in OA chondrocytes [23, 24]. In a previous study, we identified a repertoire of miRNAs during the development of rat femoral articular cartilage [25] and demonstrated that $m i R-337$ regulates chondrogenesis through a direct target, TGFBR2 [26]. Specifically, miR-181a-5p, a member of the miR-181 family, which is organized into three clusters (miR-181a/b-1, miR-181a/b-2, and $m i R-181 c / d)$, is positively correlated with chondrogenesis [25]. Meanwhile, non-hypertrophic articular and hypertrophic MSC-derived chondrocytes showed differential expression of miR-181a-5p, suggesting that its expression is altered during successive differentiation stages [27]. Moreover, miR-181a-5p is predicted to be a target of $h S B P 2$ by
TargetScanHuman7.1, and it may inhibit the expression of the important ECM protein aggrecan (ACAN) in chondrocytes, simultaneously acquiring a negative feedback function for cartilage homeostasis [28]. However, further investigation is required to understand the oxidation resistance-associated roles of miR-181a-5p in OA.

In the present study, the glutathione peroxidase-encoding genes GPX1 and GPX4 and the selenoprotein S-encoding gene $S E L S$ were examined due to their regulation by $S B P 2$. Hence, we investigated the detailed regulatory relationships among pro-inflammatory factors, miRNA, SBP2 and selenoproteins in the context of oxidation resistance in cartilage. Overall, this study provides the first comprehensive evidence for changes in pro-inflammatory factors in the cartilage antioxidant network during OA and describes the discovery of novel mediators of cartilage oxidative stress and OA pathophysiology. Therefore, our data suggest that miR-181a-5p may be useful for the development of novel early-stage diagnostic and therapeutic strategies for OA.

\section{Methods \\ Cell culture}

The human chondrosarcoma chondrocyte SW1353 cell line was obtained from the Chinese Academy of Sciences (Shanghai, China) and cultured in RPMI-1640 medium (HyClone, USA) with 10\% foetal bovine serum (ExCell, China). The murine chondroblast ATDC5 cell line was obtained from the European Collection of Cell Cultures (ECACC) and maintained in Dulbecco's Modified Eagle's medium/Ham's F12 medium (DMEM/F12, HyClone, USA) supplemented with 5\% FBS (Gibco, USA). Both cell lines were maintained in a humidified incubator with $5 \% \mathrm{CO}_{2}$ at $37{ }^{\circ} \mathrm{C}$, cultured in monolayers and grown to confluence. The medium contained $1 \%$ penicillin/streptomycin (Sigma, USA). The cells were seeded in 12-multiwell plates at $7 \times 10^{4}$ cells/well.

For the cartilage matrix degradation model, SW1353 cells were placed in FBS-free medium for more than $10 \mathrm{~h}$, and then the cells were incubated with 0 (as control), 1, 5, 10 and $20 \mathrm{ng} / \mathrm{ml}$ IL-1 $\beta$ (Sino Biological Inc., China) for $12 \mathrm{~h}$, or $10 \mathrm{ng} / \mathrm{ml} \mathrm{IL-1} \beta$ for 0 (as control), 6 , 12,24 and $48 \mathrm{~h}$. For the chondrocyte differentiation model, ATDC 5 cells were induced with $1 \times$ ITS supplement $(1 \mathrm{mg} / \mathrm{ml}$ insulin, $0.55 \mathrm{mg} / \mathrm{ml}$ transferrin and $0.5 \mu \mathrm{g} / \mathrm{ml}$ selenium) added to the medium. The chondrogenic culture medium was changed every day.

\section{Transient transfection of hsa-miR-181a-5p mimics or inhibitor sequences}

SW1353 cells were seeded for $24 \mathrm{~h}$, and $50 \mathrm{nM} h s a-$ miR-181a-5p mimics (mimic-181a-5p) or negative control (mimic-NC) (Genepharma, China) and $200 \mathrm{nM} h s a-$ miR-181a-5p inhibitor (inhibitor-181a-5p) or negative control (inhibitor-NC) (Genepharma, China) were transiently 
transfected into SW1353 cells by $1.5 \mu \mathrm{l} /$ well Lipofectamine $^{\mathrm{Tm}} 2000$ (Invitrogen, USA) according to the manufacturer's instructions. Information about miR-181a-5p is provided in Tables 1 and 2.

\section{Transient transfection of siRNAs and plasmids}

The full-length human SBP2 CDS was cloned from SW1353 chondrocyte cDNA and inserted into a $p E F G P-N 1$ vector (Invitrogen, USA). The primer sequences for the hSBP2-CDS clone are listed in Table 3. SW1353 cells were seeded for $24 \mathrm{~h}$, and $1,1.5,2$ and $4 \mu \mathrm{g}$ of the pEFGP-mSBP2-N1 vector or empty vector were transiently transfected into cells by $1.5 \mu \mathrm{l} /$ well Lipofectamine ${ }^{\mathrm{rm}} 2000$ (Invitrogen, USA). The expression of exogenous and endogenous SBP2 was determined by western blotting with an anti-SBP2 antibody after transfection for $24 \mathrm{~h}$.

Additionally, $h S B P 2$ siRNA (si-SBP2) and control siRNA (si-NC) sequences were purchased from Genepharma Biotechnology Inc. (Genepharma, China). Cell transfection was performed according to the manufacturer's instructions. For gene knockdown, SW1353 cells were seeded for $24 \mathrm{~h}$, and $50 \mathrm{nM}$ si-SBP2 (5'-GAGC CACACUACAUUGAAATT-3') or si-NC was transiently transfected into the cells by $1.5 \mu \mathrm{l} /$ well Lipofectamine $\mathrm{e}^{\mathrm{ma}}$ 2000 (Invitrogen, USA) according to the manufacturer's instructions. Knockdown efficiency was determined by western blotting after transfection for $48 \mathrm{~h}$.

\section{Patients and articular cartilage collection}

OA patients were diagnosed according to the modified Outerbridge classification by The Second Affiliated Hospital, Xi'an Jiaotong University Health Science Center. Articular cartilage samples were obtained at the time of total knee replacement (TKR) from $10 \mathrm{hu}-$ man patients with knee OA (6 women and 4 men; mean \pm SEM age: $60 \pm 8.3$ y) from Shaanxi province, China. All patients were diagnosed with Kellgren and Lawrence grade IV OA. After washing with sterile phosphate buffered saline (PBS), portions of cartilage with a damaged articular surface and portions with a smooth articular surface were used for RNA extraction and immunohistochemistry. Smooth cartilage samples were carefully assessed for any gross signs of degeneration or injury, and only normal-appearing smooth cartilage was used as an internal control (a self control). All cartilage samples were collected without fibrillation. Peripheral blood samples were obtained from 20 OA patients (14 women and 6 men; mean \pm SD age:

Table 1 Information of Mature miR-181a-5p

\begin{tabular}{lll}
\hline ID & Accession & Mature sequence (5'-3') \\
\hline hsa-miR-181a-5p & MIMAT0000256 & AACAUUCAACGCUGUCGGUGAGU \\
mmu-miR-181a-5p & MIMAT0000210 & \\
\hline
\end{tabular}

Table 2 Information of Stem-loop hsa-miR-181a

\begin{tabular}{|c|c|c|c|}
\hline ID & Accession & Location & Stem-loop sequence $\left(5^{\prime}-3^{\prime}\right)$ \\
\hline $\begin{array}{l}\text { hsa-mir-181a-1 } \\
\text { (hsa-mir-213) }\end{array}$ & MI0000289 & $1 \mathrm{q} 32.1$ & $\begin{array}{l}\text { UGAGUUUUGAGGUUGCUUC } \\
\text { AGUGAACAUUCAACGCUG } \\
\text { UCGGUGAGUUUGGAAUUA } \\
\text { AAAUCAAAACCAUCGACCGU } \\
\text { UGAUUGUACCCUAUGGCUAA } \\
\text { CCAUCAUCUACUCCA }\end{array}$ \\
\hline hsa-mir-181a-2 & MI0000269 & $9 q 33.3$ & $\begin{array}{l}\text { AGAAGGGCUAUCAGGCCAG } \\
\text { CCUUCAGAGGACUCC } \\
\text { AAGGAACAUUCAACGCUG } \\
\text { UCGGUGAGUUUGGGAUUUGAA } \\
\text { AAACCACUGACCGUUGACUGU } \\
\text { ACCUUGGGGUCCUUA }\end{array}$ \\
\hline
\end{tabular}

$66.6 \pm 5.7 \mathrm{y})$ and 20 normal control patients (14 women and 6 men; mean \pm SD age: $65.9 \pm 3.1 \mathrm{y}$ ).

Total RNA extraction and quantitative PCR analysis For RNA extraction, cartilage tissues were harvested from smooth articular surfaces and damaged articular surfaces of the same patient and chopped into pieces that were smaller than $2 \times 2 \mathrm{~mm}$. Then, the pieces were immediately frozen in liquid nitrogen. Total RNA was isolated from cells, tissue pieces or plasma samples using TRIzol $^{\bullet}$ (Invitrogen, USA). cDNA was synthesized from $2 \mu \mathrm{g}$ of total RNA according to the manufacturer's instructions (RevertAid $^{\mathrm{Ts}}$; Fermentas, Canada) in a final volume of $20 \mathrm{ml}$ and stored at $-20{ }^{\circ} \mathrm{C}$ until use. Furthermore, miRNA-cDNA was obtained using the One Step PrimeScript ${ }^{\oplus}$ miRNA cDNA Synthesis Kit (Takara, Japan).

Both mRNA and miRNA expression was tested by $10 \mu \mathrm{l}$ real-time quantitative PCR (RT-qPCR), which was performed on an iQ5 real-time PCR detection system (Bio-Rad, Hercules, CA, USA) with SYBR ${ }^{\oplus}$ Premix Ex $\mathrm{Taq}^{\mathrm{Tm}}$ II (TaKaRa, Japan). Relative gene expression was normalized against GAPDH expression in SW1353 cells or $\beta$-Actin expression in ATDC5 cells. Additionally, let-7a was used as the internal reference for $m i R-181 a-5 p$. The procedure for miRNA-cDNA qPCR consisted of two-step amplification: pre-denaturation at $95{ }^{\circ} \mathrm{C}$ for $10 \mathrm{~s}$, followed by PCR amplification with 40 cycles of $95{ }^{\circ} \mathrm{C}$ for $5 \mathrm{~s}$ and $60{ }^{\circ} \mathrm{C}$ for $20 \mathrm{~s}$. Information about the primers and PCR amplification is provided in Tables 4, 5 and 6.

\section{Protein sample preparation and western blotting}

Total protein samples from SW1353 cells or ATDC5 cells (10-20 $\mu \mathrm{g})$ were separated by $10 \%$ SDS-PAGE and transferred to PVDF membranes (EMD Millipore, Darmstadt,

Table $\mathbf{3}$ Information of human primers for hSBP2-CDS

\begin{tabular}{ll}
\hline Gene & Sequence $\left(5^{\prime}{ }^{\prime} 3^{\prime}\right)$ \\
\hline hSBP2-CDS- & CAGGTCGGATCCAGACCCGGGgccaccATGGCGTCG \\
Forward & GAGGGG \\
hSBP2-CDS- & TCTGTAGAATTCGGTCCCGGGTAAATCAAATTCATCAT \\
Reverse & \\
\hline
\end{tabular}


Table 4 Information of miRNA-181a-5p for Real-time PCR

\begin{tabular}{lll}
\hline MicroRNAs & Accession NO. & Forward primer (5'-3') \\
\hline hsa-miRNA-181a-5p & MIMAT0000858 & CGCAACATTCAACGCTGTC \\
hsa-let-7a & MIMAT0000774 & CGCTGAGGTAGTAGGTGT \\
Reverse primer: GTGCAGGGTCCGAGGT & \\
\hline
\end{tabular}

Germany). After blocking with 3\% non-fat milk in TBST buffer, the membranes were incubated with primary antibodies followed by secondary antibodies conjugated to horseradish peroxidase (HRP) and visualized using an ECL detection system (EMD Millipore, Darmstadt, Germany) on a chemiluminescence imaging system. The primary antibodies included anti-SBP2 (1:500, CA, USA), anti-GPX1 (1:2000, CA, USA), anti-MMP13 (1:1000, Abcam, USA) and anti- $\beta$-ACTIN (1:2000, Proteintech, China). The following secondary antibodies were purchased from Beyotime Biotech (Jiangsu, China): horseradish peroxidase-coupled anti-rabbit (1:5000) and anti-mouse (1:5000).

\section{Immunohistochemistry staining}

After measuring intrinsic peroxidase activity, articular cartilage sections were blocked with $3 \%$ hydrogen peroxide $\left(\mathrm{H}_{2} \mathrm{O}_{2}\right)$ and then incubated with $1.5 \%$ BSA for $1 \mathrm{~h}$. The sections were covered with anti-SBP2 antibodies (1:250, CA, USA) and incubated at $4{ }^{\circ} \mathrm{C}$ in a wet box. After $14 \mathrm{~h}$, all sections were rinsed with PBS and then sequentially incubated with biotinylated secondary antibody for $1 \mathrm{~h}$ and DAB reagent (Boster, Wuhan, China) for $5 \mathrm{~min}$ at room temperature. Chromogenic reactions were terminated once claybank regions were observed under a microscope. Rabbit IgG was used as a negative control.

\section{Statistical analysis}

Data are presented as the mean \pm SEM. The statistical significance of pathological data was calculated by using the Mann-Whitney $U$ test. Means of two groups were compared using Student's t test, and statistical significance was achieved at $P<0.05$ in all tests $(*: P<0.05$, **: $P<0.01$ and $*: P<0.001)$. All analyses were performed

Table 5 Information of mouse primers for Real-time PCR

\begin{tabular}{llcc}
\hline Gene & Sequence $\left(5^{\prime}{ }^{\prime} 3^{\prime}\right)$ & $\begin{array}{l}\text { Product size } \\
(\mathrm{bp})\end{array}$ & $\begin{array}{l}\text { Annealing } \\
\text { temperature }\left({ }^{\circ} \mathrm{X}\right)\end{array}$ \\
\hline Sbp2 & $\begin{array}{l}\text { Forward:CTGCTCCAAAGGCC } \\
\text { AAAG }\end{array}$ & 195 & 60 \\
& $\begin{array}{l}\text { Reverse:GTGATTGCCCTCTG } \\
\text { TGTCTTC }\end{array}$ & & \\
$\beta-$ & Forward:AACAGTCCGCCTAG & 281 & 60 \\
Actin & AAGCAC & & \\
& Reverse:CGTTGACATCCGTA & & \\
& AAGACC & & \\
\hline
\end{tabular}

Table 6 Information of human primers for Real-time PCR

\begin{tabular}{|c|c|c|c|}
\hline Gene & Sequence $\left(5^{\prime}-3^{\prime}\right)$ & $\begin{array}{l}\text { Product } \\
\text { size }(b p)\end{array}$ & $\begin{array}{l}\text { Annealing } \\
\text { temperature }\left({ }^{\circ} \mathrm{C}\right)\end{array}$ \\
\hline \multirow[t]{2}{*}{ SBP2 } & $\begin{array}{l}\text { Forward: } \\
\text { CCGCAGATTCAGGGATTACT }\end{array}$ & 92 & 60 \\
\hline & $\begin{array}{l}\text { Reverse: } \\
\text { CTTGGAAACGGACCAGTTCT }\end{array}$ & & \\
\hline \multirow[t]{2}{*}{ ACAN } & $\begin{array}{l}\text { Forward: } \\
\text { GGCATTTCAGCGGTTCCTTCTC }\end{array}$ & 135 & 60 \\
\hline & $\begin{array}{l}\text { Reverse: } \\
\text { AGCAGTTGTCTCCTCTTCTACGG }\end{array}$ & & \\
\hline \multirow[t]{2}{*}{ MMP13 } & $\begin{array}{l}\text { Forward: } \\
\text { AATATCTGAACTGGGTCTTCCAAAA }\end{array}$ & 102 & 60 \\
\hline & $\begin{array}{l}\text { Reverse: } \\
\text { CAGACCTGGTITCCTGAGAACAG }\end{array}$ & & \\
\hline \multirow[t]{2}{*}{ COL2A1 } & $\begin{array}{l}\text { Forward: } \\
\text { TGGACGATCAGGCGAAACC }\end{array}$ & 244 & 62 \\
\hline & $\begin{array}{l}\text { Reverse: } \\
\text { GCTGCGGATGCTCTCAATCT }\end{array}$ & & \\
\hline \multirow[t]{2}{*}{$G P \times 1$} & $\begin{array}{l}\text { Forward: } \\
\text { AAGCTCATCACCTGGTCTCC }\end{array}$ & 124 & 60 \\
\hline & $\begin{array}{l}\text { Reverse: } \\
\text { CGATGTCAATGGTCTGGAAG }\end{array}$ & & \\
\hline \multirow[t]{2}{*}{ GPx4 } & $\begin{array}{l}\text { Forward: } \\
\text { GCTGTGGAAGTGGATGAAGA }\end{array}$ & 105 & 60 \\
\hline & $\begin{array}{l}\text { Reverse: } \\
\text { TGAGGAACTGTGGAGAGACG }\end{array}$ & & \\
\hline \multirow[t]{2}{*}{ SELS } & $\begin{array}{l}\text { Forward: } \\
\text { CACCTATGGCTGGTACATCG }\end{array}$ & 130 & 60 \\
\hline & $\begin{array}{l}\text { Reverse: } \\
\text { AACATCAGGTTCCACAGCAG }\end{array}$ & & \\
\hline \multirow[t]{2}{*}{ GAPDH } & $\begin{array}{l}\text { Forward: } \\
\text { CACCCACTCCTCCACCTTTG }\end{array}$ & 110 & 64 \\
\hline & $\begin{array}{l}\text { Reverse: } \\
\text { CCACCACCCTGTTGCTGTAG }\end{array}$ & & \\
\hline
\end{tabular}

using GraphPad Prism 6.0 (GraphPad Software, San Diego, CA, USA).

\section{Results}

Both hsa-miR-181a-5p and SBP2 are regulated by IL-1 $\beta$ in chondrocytes

IL-1 $\beta$ was selected to stimulate SW1353 cells, and hsamiR-181a-5p expression levels were determined by stem loop RT-qPCR. The expression of $h s a-m i R-181 a-5 p$ and $M M P 13$ continuously and robustly increased after treatment with $10 \mathrm{ng} / \mathrm{ml} \mathrm{IL-1 \beta}$ for 0 (as a control), 6, 12, 24 and $48 \mathrm{~h}$ in SW1353 cells, while SBP2 and GPX1 expression was continuously and sharply reduced at the mRNA level (Fig. 1a). Meanwhile, SBP2, GPX1 and MMP13 expression at the protein level showed the same patterns observed at the mRNA level (Fig. 1b). The expression of $h s a-m i R-181 a-5 p$ increased, and the expression of SBP2 at the mRNA level reduced over time after treatment 


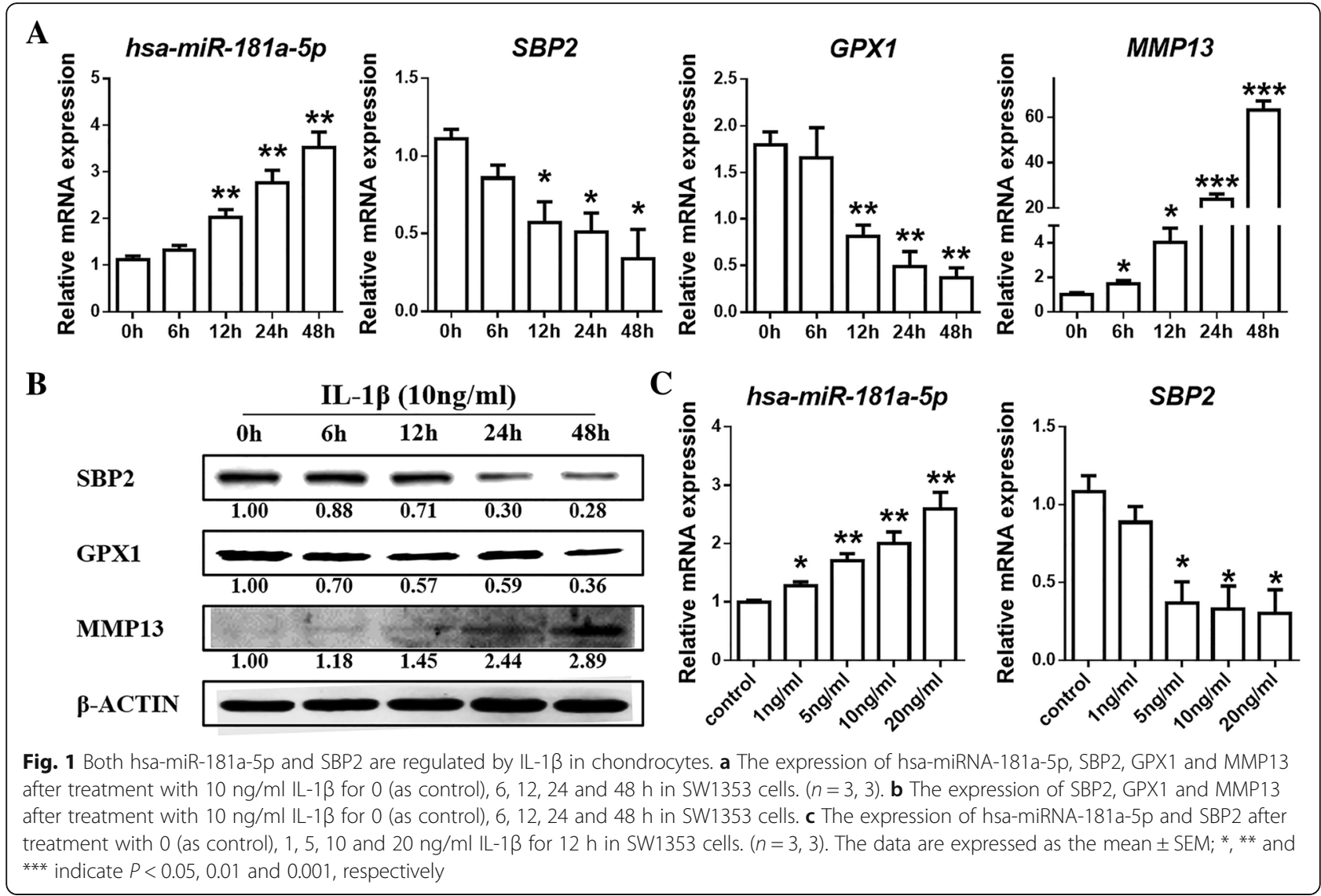

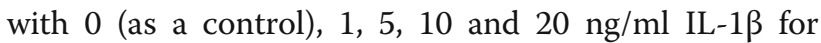
$12 \mathrm{~h}$ (Fig. 1c).

SBP2 regulated the biosynthesis of three selenoproteins and oxidation resistance in chondrocytes

To assess the role of SBP2 in chondrocytes, we constructed recombinant $h S B P 2-C D S$ clones and si-SBP2 (Fig. 2a) and transfected these constructs into SW1353 cells. Exogenous SBP2 (122 kDa, Fig. 2b) showed remarkable concentration-dependent up-regulation with pEGFP-N1-mSBP2. Overall, taking into consideration both endogenous $S B P 2$ (95 kDa, Fig. 2b) and exogenous $S B P 2,2 \mu \mathrm{g}$ of $p E G F P-N 1-m S B P 2$ was the most suitable treatment to achieve $S B P 2$ over-expression. SBP2 over-expression $(P=0.0003)$ in SW1353 cells elevated both GPX1 $(P=0.0064)$ and GPX4 $(P=0.0215) \mathrm{mRNA}$ levels, whereas SELS $(P=0.4532)$ induced no evident changes (Fig. 2c). On the other hand, when $S B P 2$ levels were specifically reduced by $s i-S B P 2(P=0.0087)$, both GPX1 $(P=0.0097)$ and GPX4 $(P=0.0431)$ mRNA levels, but not SELS levels $(P=0.2093)$, were also down-regulated significantly (Fig. 2d). Meanwhile, total GPXs activity was increased $(P=0.0097)$ by $S B P 2$ over-expression, and total GPXs activity was reduced $(P$ $=0.0023$ ) under SBP2 knockdown conditions (Fig. 2e).
Transfection of miR-181a-5p affects chondrocyte phenotype and oxidation resistance through SBP2

To confirm the roles of miR-181a-5p in chondrocytes, a miR-181a-5p mimic $(P=0.0022)$ or a $m i R-181 a-5 p$ inhibitor $(P=0.0108)$ was applied to alter miR-181a-5p levels (Additional file 1: Figure S1). The expression of cartilage-specific genes such as COL2A1, ACAN and $M M P 13$ and total GPXs activity were detected in SW1353 cells after transfection for $24 \mathrm{~h}$. First, mimicmiR-181a-5p down-regulated $A C A N(P=0.0052)$ and up-regulated $M M P 13(P=0.0095)$ (Fig. 3a), while inhibitor-miR-181a-5p also significantly up-regulated $M M P 13$ $(P=0.0319)$ (Fig. 3b). Furthermore, both SBP2 $(P=$ $0.0209)$ and SBP2 were significantly down-regulated in SW1353 cells when miR-181a-5p was up-regulated by mimic-181a-5p (Fig. 3c and d). In contrast, neither SBP2 nor SBP2 expression changed when miR-181a-5p was down-regulated by inhibitor-181a-5p (Fig. 3c and d). Meanwhile, total GPXs activity was reduced $(P=0.0145)$ by miR-181a-5p over-expression, and total GPXs activity was increased $(P=0.0143)$ under miR-181a-5p knockdown conditions (Fig. 3e). In addition, ITS treatment was applied to cultured cells for 14 days as described previously to induce ATDC5 cells to differentiate in vitro [29], and then the expression of mmu-miR-181a-5p, Sbp2 and 

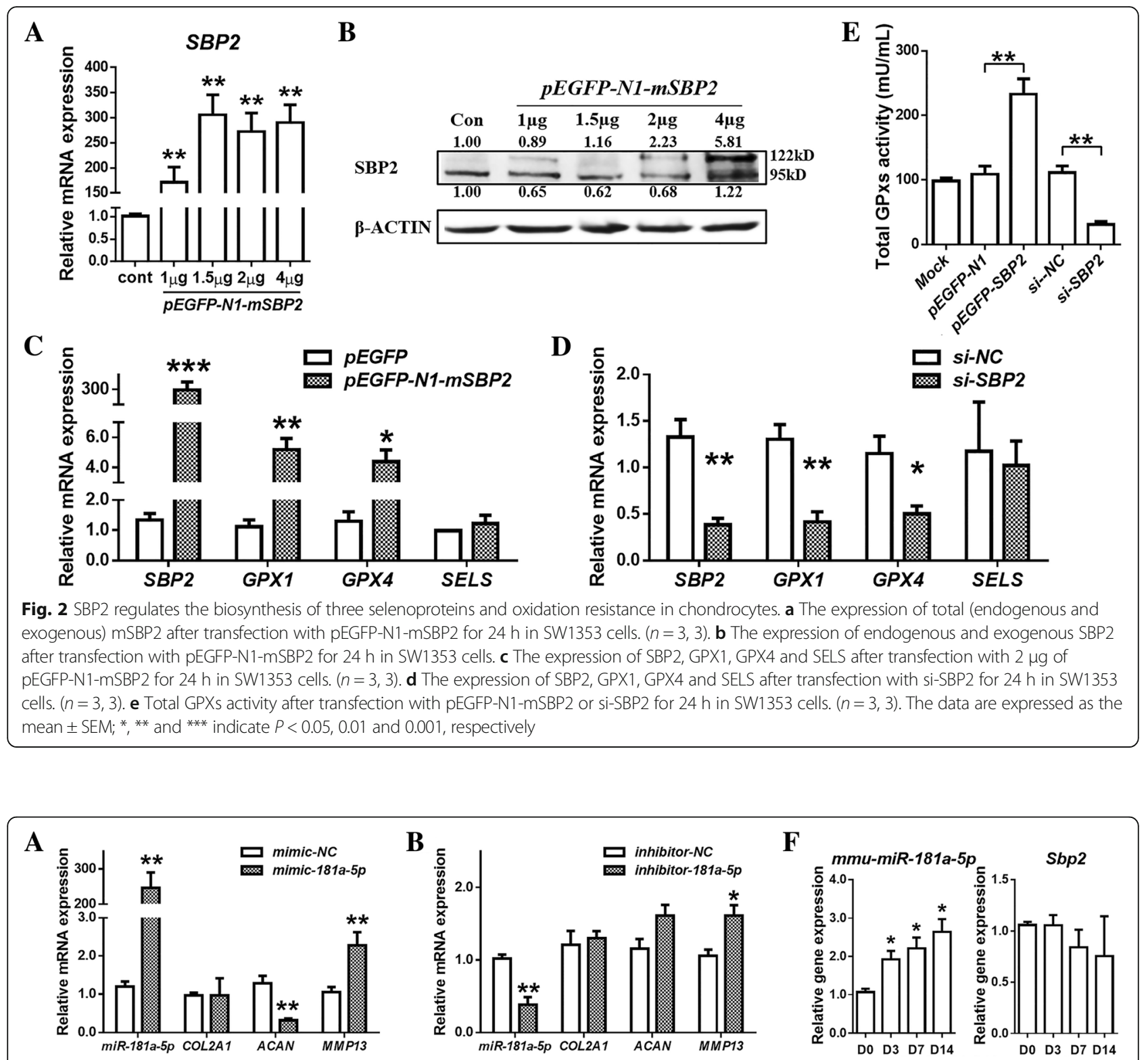

C

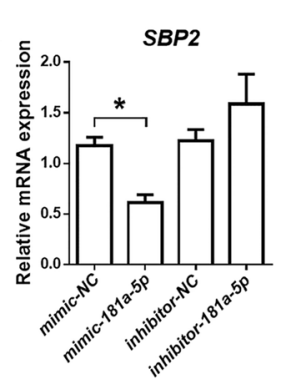

D

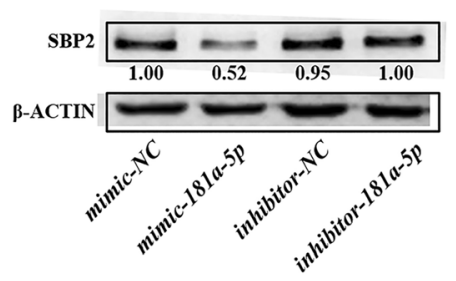

$\mathbf{E}$

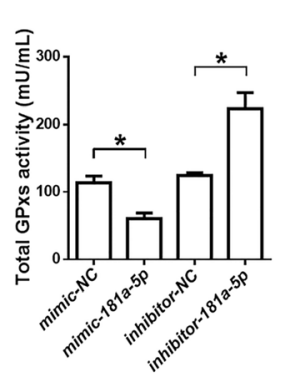

SBP2

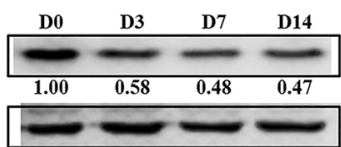

Fig. 3 Transfection of miR-181a-5p affects the phenotype and oxidation resistance of chondrocytes through SBP2. a The expression of hsa-miR-181a-5p, COL2A1, ACAN and MMP13 after transfection with mimic-181a-5p for $24 \mathrm{~h}$ in SW1353 cells. $(n=3,3)$. b The expression of hsa-miR-181a-5p, COL2A1, ACAN and MMP13 after transfection with inhibitor-181a-5p for $24 \mathrm{~h}$ in SW1353 cells. $(n=3,3)$. c The expression of SBP2 after transfection with mimic$181 \mathrm{a}-5 \mathrm{p}$ or inhibitor-181a-5p for $24 \mathrm{~h}$ in SW1353 cells. $(n=3,3)$. $\mathbf{d}$ The expression of SBP2 after transfection with mimic-181a-5p or inhibitor-181a-5p for $24 \mathrm{~h}$ in SW1353 cells. e Total GPXs activity after transfection with mimic-181a-5p or inhibitor-181a-5p for $24 \mathrm{~h}$ in SW1353 cells. ( $n=3,3)$. f The expression of mmu-miR-181a-5p, Sbp2 and SBP2 following ITS treatment in ATDC5 cells. $(n=3,3)$. The data are expressed as the mean \pm SEM; * ${ }^{* *}$ and ${ }^{* * *}$ indicate $P<0.05,0.01$ and 0.001 , respectively 
SBP2 was detected. With chondrocyte differentiation, the expression of $m m u-m i R-181 a-5 p$ showed remarkable up-regulation at D3 $(P=0.0258), \mathrm{D} 7(P=0.0178)$ and D14 $(P=0.0103)$, while SBP2 protein expression was significantly reduced, although the expression of $S b p 2$ was almost constant (Fig. 3f).

\section{The expression of hsa-miRNA-181a-5p, SBP2 and selenoproteins in $O A$ cartilage}

Cartilage tissues were obtained from 8 OA patients to detect the expression of miRNA-181a-5p, SBP2 and three pivotal selenoproteins. OA smooth cartilage and damaged cartilage from the same patients undergoing TKR were separated (Fig. 4a). Total RNA was extracted, and RT-qPCR was performed. According to a paired Student's $\mathrm{t}$ test, miRNA-181a-5 $p$ expression levels were significantly higher $(P=0.0114)$ in damaged cartilage than in smooth cartilage of OA patients (Fig. 4b). Meanwhile, although $S B P 2$ mRNA expression was unattenuated in damaged cartilage (Fig. 4c), SBP2 protein expression was reduced in damaged cartilage (Fig. 4d). Furthermore, GPX1 $(P=0.0183)$ and GPX4 $(P=0.0149)$ were down-regulated in damaged OA cartilage (Fig. 4e), while SELS showed no significant changes (Fig. 4e).

\section{The expression of hsa-miRNA-181a-5p, SBP2 and selenoproteins in peripheral blood}

Peripheral blood was collected from 20 healthy controls and 20 OA patients. To detect the expression of miRNA-181a-5p, SBP2, GPX1, GPX4 and SELS, total RNA from peripheral blood was extracted, and RT-qPCR was performed. The expression of hsa-miRNA-181a-5p $(P=$ 0.0329 ) in OA peripheral blood was significantly higher than that in normal controls (Fig. 5a), while $S B P 2(P=$ $0.0061)$ and GPX1 $(P=0.0111)$ were both lower in OA peripheral blood than in normal controls (Fig. $5 \mathrm{~b}$ and c). In addition, SELS $(P=0.8160)$ showed no statistically significant differences (Fig. 5d), and GPX4 was not detected (data not shown). These results suggested that hsa-miR$N A-181 a-5 p$ is a potential diagnostic biomarker for OA.

\section{Discussion}

To explore whether miR-181a-5p and SBP2 are involved in OA pathogenesis, we established an IL-1 $\beta$ model

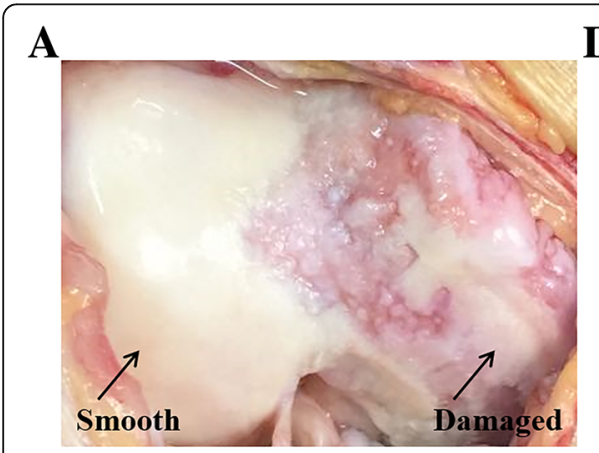

D
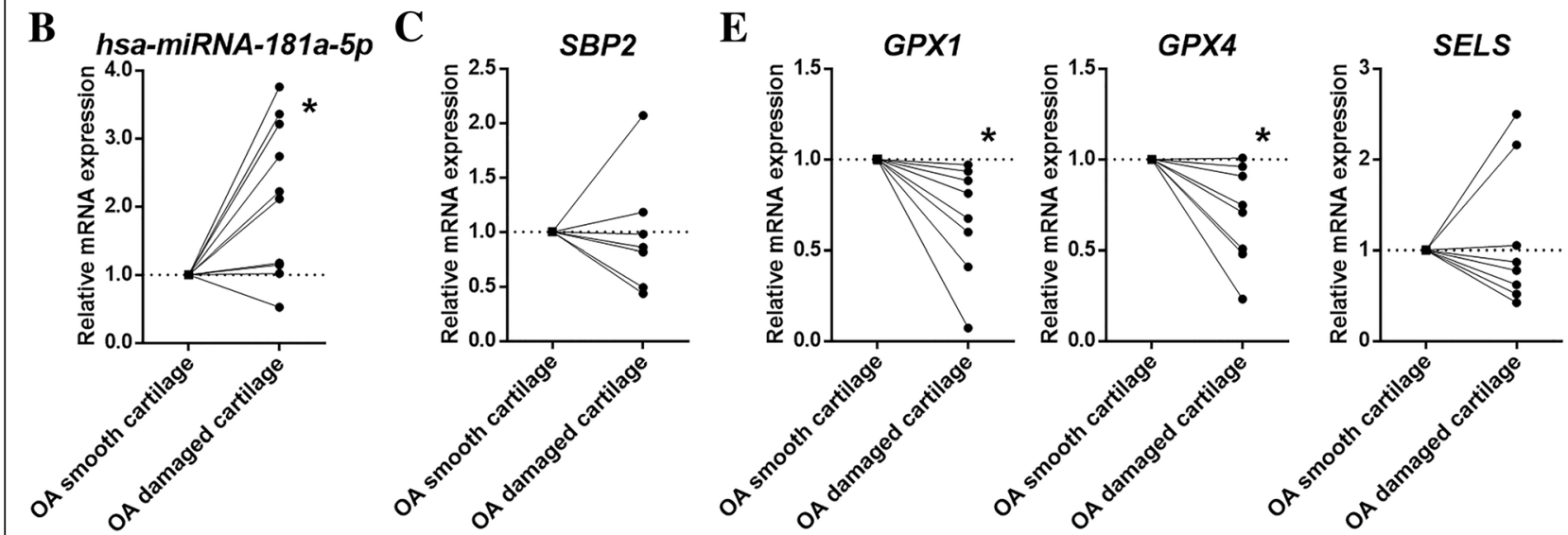

Fig. 4 The expression of hsa-miRNA-181a-5p, SBP2 and selenoproteins in OA cartilage. a OA smooth cartilage and damaged cartilage from the same patients undergoing total knee replacement. $\mathbf{b}$ The expression of $h s a-m i R N A-181 a-5 p$ in smooth cartilage and damaged cartilage from the same OA cartilage sample. $(n=10)$. c The expression of SBP2 in smooth cartilage and damaged cartilage from the same OA cartilage sample. $(n=7)$. $\mathbf{d}$ The expression of SBP2 in smooth cartilage and damaged cartilage from the same OA cartilage sample. e The expression of GPX1, GPX4 and SELS in smooth cartilage and damaged cartilage from the same OA cartilage sample. $(n=8)$. The data were expressed as the mean \pm SEM; ${ }^{*},{ }^{* *}$ and ${ }^{* * *}$ indicate $P<0.05$, 0.01 and 0.001 , respectively 

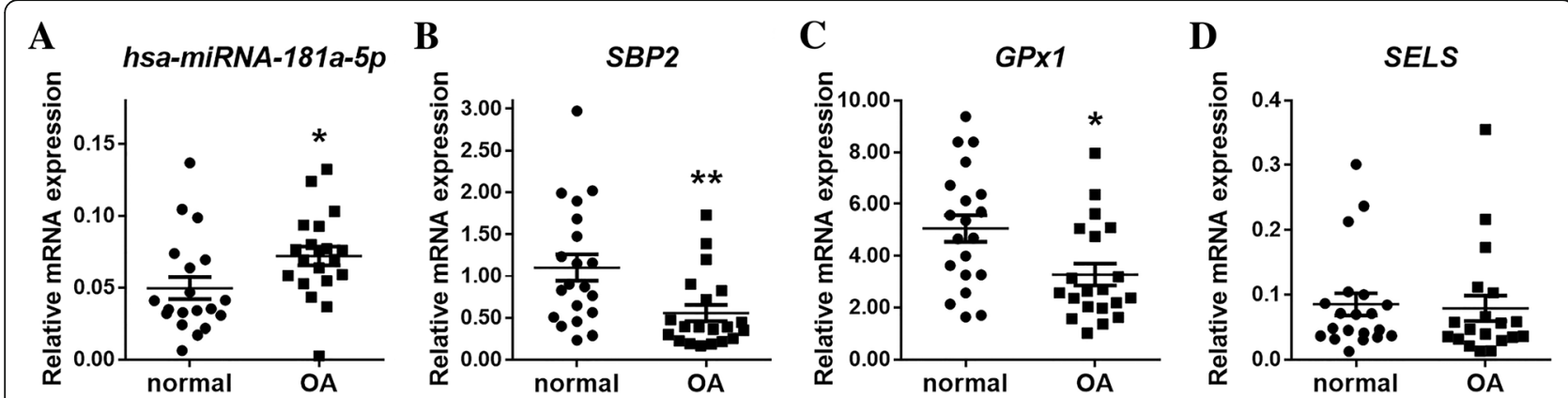

Fig. 5 The expression of hsa-miRNA-181a-5p, SBP2 and selenoproteins in peripheral blood. a The expression of hsa-miRNA-181a-5p in the peripheral blood of healthy controls and OA patients. $(n=19,20)$. b The expression of SBP2 in the peripheral blood of healthy controls and OA patients. $(n=20$, 20). $\mathbf{c}$ The expression of GPX1 in the peripheral blood of healthy controls and OA patients. $(n=20,20)$. $\mathbf{d}$ The expression of SELS in the peripheral blood of healthy controls and OA patients. $(n=20,19)$. The data are expressed as the mean \pm SEM; ** ** and ${ }^{* * *}$ indicate $P<0.05,0.01$ and 0.001 , respectively

using the chondrocyte SW1353 cell line. The results showed that IL-1 increased hsa-miR-181a-5p and decreased SBP2 in a time- and dose-dependent manner, while both hsa-miR-181a-5p and SBP2 seemed to participate in the catabolism pathway and oxidative stress in chondrocytes induced by IL-1 $\beta$. This finding is in line with our expectation that pro-inflammatory cytokines induce miR-181a-5p up-regulation in chondrocytes along with SBP2 down-regulation. Coincidentally, miR-181a-5p up-regulates the expression of caspase-3, PARP, MMP-2, and MMP-9 while repressing chondrocyte proliferation and promoting chondrocyte apoptosis in OA [22, 30].

Next, we used recombinant plasmids and siRNA sequences targeting SBP2 to up- or down-regulate the expression of this gene in SW1353 cells. To investigate SBP2-mediated selenoprotein synthesis, GPX1, GPX4 and SELS were selected as representative selenoproteins expressed by chondrocytes in this study not only because these proteins exhibit differential cellular localization and fulfil different functions in physiological and pathological processes in various cells but also because the affinity of their SECIS binding with 'UGA' recoding has been categorized as strong, moderate and weak, respectively [31,32]

As crucial antioxidant enzymes, GPX1 and GPX4 were regulated by $S B P 2$ up- or down-regulation, while $S E L S$ expression levels were always stabilized; these expression patterns are attributable to the differential SECIS affinities and SBP2 binding efficiencies of these proteins. Our findings suggest that $S B P 2$ expression did not align with selenoprotein expression regulation, which affected total GPXs activity and oxidation resistance in chondrocytes. Oxidative damage due to the concomitant overproduction of ROS is present in ageing and OA cartilage [33]. Predictably, oxidative stress destroys normal physiological signalling and contributes to OA [13]. The synergy between blocked selenoprotein expression and disordered metabolism of the articular cartilage ECM induces chondrocyte apoptosis and contributes to cartilage destruction $[9,34]$ In summary, selenoprotein biosynthesis leads to decreased antioxidant stress.

Additionally, we modulated miR-181a-5p expression by using mimic and inhibitor sequences in SW1353 cells. The expression of miR-181a-5p showed remarkable up-regulation, while SBP2 protein expression was significantly reduced. Unexpectedly, SBP2 expression did not change after miR-181a-5p knockdown, which implies that a very complex regulatory network and multiple modulators are involved in SBP2 expression. Furthermore, SBP2 showed a significant negative correlation with $m i R-181 a-5 p$ during the induced differentiation of ATDC5 cells. These results suggest that hsa-miR-181a-5p affects the chondrocyte phenotype by altering oxidation resistance.

The most effective antioxidants are members of the GPx family, but the mechanisms underlying their effects on OA chondrocytes under oxidative stress are not yet fully understood [9]. Our results established that miR-181a-5p regulated total GPXs activity by decreasing the expression of $S B P 2$ in cartilage, leading to chondrocyte apoptosis and cellular damage induced by ROS. SBP2 is required for protection against ROS-induced cellular damage and increased cell survival [35]. For instance, gene mutations in SBP2 decreased the expression of several selenoproteins, resulting in a complex multisystem selenoprotein deficiency disorder in humans [36], and lipid peroxidation products mediated by free radicals increased in the blood [37]. Further, miR-34a, miR-146a, SOD2, CAT, GPXs and NRF2 are subjected to $\mathrm{H}_{2} \mathrm{O}_{2}$ stimulus in OA chondrocytes [24]. Meanwhile, miR-9 is a OA-related effects of oxidative stress in chondrocytes through targets SIRT1 [23].

Finally, we discovered that miRNA-181a-5p expression was increased, and SBP2 protein and GPX1 and GPX4 mRNA expression were reduced in damaged cartilage. These results suggest that hsa-miRNA-181a-5p, GPX1, 
GPX4 and SBP2 all participate in the OA cartilage damage process to a certain extent. Despite the inadequate number of samples, our peripheral blood data partly support the hypothesis that miR-181a-5p is released in plasma and may facilitate early-stage diagnosis of OA because it induces ROS to damage cartilage proteins. Currently, few blood-based tests are used for the detection of early-stage OA.

\section{Conclusions}

We have reported a novel pathway in cartilage. Pro-inflammatory factors mediate miR-181a-5p expression, and then $m i R-181 a-5 p$ regulates the pivotal selenoproteins GPX1 and GPX4 through its target SBP2, resulting in alterations to the overall activity of GPXs, which are the most important oxidation resistance proteins in cartilage. Oxidation resistance involves a series of antioxidants that overcome ROS-related stress to maintain ECM metabolism balance and protect the essential physiological functions of cartilage.

\section{Additional file}

Additional file 1: Figure S1. The illustration of possible pathways about miRNA-181a-5p regulated selenoproteins in chondrocytes. The expression of has-miR-181a-5p after transfected mimic-181a-5p or inhibitor-181a-5p for $24 \mathrm{~h}$ in SW1353 cells. $(n=3,3)$. The data were expressed as means \pm SEM ${ }^{*}{ }^{* *}$ and ${ }^{* * *}$ stand for $P<0.05,0.01$ and 0.001 respectively. (TIF $535 \mathrm{~kb}$ )

\section{Abbreviations}

ACAN: Aggrecan; COL2: type-II collagen; ECM metabolic: Extracellular matrix HRP: Horseradish peroxidase; IL-1 $\beta$ : Including interleukin-1; IL-6: Interleukin-6; inhibitor-181a-5p: miR-181a-5p inhibitor; mimic-181a-5p: miR-181a-5p mimics; OA: Osteoarthritis; PBS: Phosphate buffered saline; ROS: Reactive oxygen species; Se: Selenium; Sec: Selenocysteine; SECIS: Sec insertion sequence; SECISBP2 or SBP2: Sec insertion sequence binding protein 2; Sel: Selenoprotein; TKR: Total knee replacement; TNF-a: Tumour necrosis factor-a

\section{Funding}

This work was supported by grants from the National Natural Science Foundation of China (Project No. 81371986, 81772410), the Shaanxi province science and technology project (2016SF-187).

\section{Availability of data and materials} Not applicable.

\section{Authors' contributions}

All authors have made substantial contributions to: (1) the conception and design of the study, or acquisition of data, or analysis and interpretation of data, (2) drafting the article or revising it critically for important intellectual content, (3) final approval of the version to be submitted. JX finished the most of experiments, analysis and interpretation of the data and wrote the original manuscript. ZM was involved in conception and design of the study, analysis and interpretation of the data, drafting of the article, critical revision of the article for important intellectual content, and final approval of the article. ZX was involved in the acquisition, analysis (the miRNA expression) and interpretation of the data, assembly of the data, critical revision of the article for important intellectual content, and final approval of the article. BC was involved in the analysis and interpretation of the data, collection and assembly of the data, critical revision of the article for important intellectual content, and final approval of the article. BL was involved in the collection the samples and interpretation of the data, collection and assembly of the data, critical revision of the article for important intellectual content, and final approval of the article. FZ was involved in the analysis (histological examination by staining with $\mathrm{IHC}$ ) and interpretation of the data, assembly of the data, critical revision of the article for important intellectual content, and final approval of the article. YH was involved in the analysis (cell culture) and interpretation of the data, assembly of the data, logistical support, critical revision of the article for important intellectual content, and final approval of the article. KW critically revised the article for important intellectual content, take responsibility for the integrity of the work as a whole. JS was involved in conception and design of the study, got the funds, analysis and interpretation of the data, critical revision of the article for important intellectual content, and final approval of the article.

\section{Authors' information}

Kunzheng Wang, the corresponding author, is the Chairman of Chinese Orthopedic Association.

\section{Ethics approval and consent to participate}

This study was performed with the approval of the Ethics Committee of the Xi'an Jiaotong University Health Science Center.

All of 10 donors of OA cartilage provided full written informed consent and "Consent to publish" before the operative procedure.

\section{Consent for publication}

Not applicable.

\section{Competing interests}

The authors declare that they have no competing interests.

\section{Publisher's Note}

Springer Nature remains neutral with regard to jurisdictional claims in published maps and institutional affiliations.

\section{Author details}

${ }^{1}$ Department of Orthopaedics, The Second Affiliated Hospital, Xi'an Jiaotong University Health Science Center, 157 West 5th Road, Xi'an, Shaanxi 710004, People's Republic of China. ${ }^{2}$ Department of Biochemistry and Molecular Biology, School of Basic Medical Sciences, Xi'an Jiaotong University Health Science Center, Xi'an, Shaanxi 710061, People's Republic of China. ${ }^{3}$ Beaurau of healthcare, Shaanxi Health and Family Planning Commission, Xi'an, Shaanxi 710000, People's Republic of China.

Received: 21 April 2018 Accepted: 23 September 2018

Published online: 05 October 2018

\section{References}

1. Loeser RF, Collins JA, Diekman BO. Ageing and the pathogenesis of osteoarthritis. Nat Rev Rheumatol. 2016;12(7):412-20.

2. Mobasheri A, Rayman MP, Gualillo O, Sellam J, van der Kraan P, Fearon U. The role of metabolism in the pathogenesis of osteoarthritis. Nat Rev Rheumatol. 2017:13(5):302-11.

3. Kapoor M, Martel-Pelletier J, Lajeunesse D, Pelletier JP, Fahmi H. Role of proinflammatory cytokines in the pathophysiology of osteoarthritis. Nat Rev Rheumatol. 2011;7(1):33-42.

4. Mitchell PG, Magna HA, Reeves LM, Lopresti-Morrow LL, Yocum SA, Rosner PJ, Geoghegan KF, Hambor JE. Cloning, expression, and type II collagenolytic activity of matrix metalloproteinase-13 from human osteoarthritic cartilage. J Clin Invest. 1996:97(3):761-8.

5. Wang M, Sampson ER, Jin H, Li J, Ke QH, Im HJ, Chen D. MMP13 is a critical target gene during the progression of osteoarthritis. Arthritis Res Ther. 2013; 15(1):R5.

6. Kim JH, Jeon J, Shin M, Won Y, Lee M, Kwak JS, Lee G, Rhee J, Ryu JH, Chun $\mathrm{CH}$, et al. Regulation of the catabolic cascade in osteoarthritis by the zincZIP8-MTF1 axis. Cell. 2014;156(4):730-43.

7. Corciulo C, Lendhey M, Wilder T, Schoen H, Cornelissen AS, Chang G, Kennedy OD, Cronstein BN. Endogenous adenosine maintains cartilage homeostasis and exogenous adenosine inhibits osteoarthritis progression. Nat Commun. 2017:8:15019.

8. Jeon $\mathrm{OH}$, Kim C, Laberge RM, Demaria M, Rathod S, Vasserot AP, Chung JW Kim DH, Poon Y, David N, et al. Local clearance of senescent cells attenuates the development of post-traumatic osteoarthritis and creates a pro-regenerative environment. Nat Med. 2017;23(6):775-81. 
9. Labunskyy VM, Hatfield DL, Gladyshev VN. Selenoproteins: molecular pathways and physiological roles. Physiol Rev. 2014;94(3):739-77.

10. Kryukov GV, Castellano S, Novoselov SV, Lobanov AV, Zehtab O, Guigo R, Gladyshev VN. Characterization of mammalian selenoproteomes. Science. 2003;300(5624):1439-43.

11. Lu J, Holmgren A. Selenoproteins. J Biol Chem. 2009;284(2):723-7.

12. Issa R, Boeving M, Kinter M, Griffin TM. Effect of biomechanical stress on endogenous antioxidant networks in bovine articular cartilage. J Orthop Res. 2018;36(2):760-9.

13. Collins JA, Wood ST, Nelson KJ, Rowe MA, Carlson CS, Chubinskaya S, Poole $L B$, Furdui CM, Loeser RF. Oxidative stress promotes Peroxiredoxin Hyperoxidation and attenuates pro-survival signaling in aging chondrocytes. J Biol Chem. 2016;291(13):6641-54.

14. Driscoll DM, Copeland PR. Mechanism and regulation of selenoprotein synthesis. Annu Rev Nutr. 2003;23:17-40.

15. Takeuchi A, Schmitt D, Chapple C, Babaylova E, Karpova G, Guigo R, Krol A, Allmang C. A short motif in Drosophila SECIS binding protein 2 provides differential binding affinity to SECIS RNA hairpins. Nucleic Acids Res. 2009; 37(7):2126-41.

16. Donovan J, Caban K, Ranaweera R, Gonzalez-Flores JN, Copeland PR. A novel protein domain induces high affinity selenocysteine insertion sequence binding and elongation factor recruitment. J Biol Chem. 2008; 283(50):35129-39.

17. Downey CM, Horton CR, Carlson BA, Parsons TE, Hatfield DL, Hallgrimsson B, Jirik FR. Osteo-chondroprogenitor-specific deletion of the selenocysteine tRNA gene, Trsp, leads to chondronecrosis and abnormal skeletal development: a putative model for Kashin-Beck disease. PLoS Genet. 2009; 5(8):e1000616.

18. Papp LV, Wang J, Kennedy D, Boucher D, Zhang Y, Gladyshev VN, Singh RN, Khanna KK. Functional characterization of alternatively spliced human SECISBP2 transcript variants. Nucleic Acids Res. 2008;36(22):7192-206.

19. Anestal K, Arner ES. Rapid induction of cell death by seleniumcompromised thioredoxin reductase 1 but not by the fully active enzyme containing selenocysteine. J Biol Chem. 2003;278(18):15966-72.

20. Vicente R, Noel D, Pers YM, Apparailly F, Jorgensen C. Deregulation and therapeutic potential of microRNAs in arthritic diseases. Nat Rev Rheumatol. 2015.

21. Nugent M. MicroRNAs: exploring new horizons in osteoarthritis: Osteoarthritis and cartilage / OARS, Osteoarthritis Research Society; 2015.

22. Nakamura A, Rampersaud YR, Sharma A, Lewis SJ, Wu B, Datta P, Sundararajan K, Endisha H, Rossomacha E, Rockel JS, et al. Identification of microRNA-181a-5p and microRNA-4454 as mediators of facet cartilage degeneration. JCI insight. 2016;1(12):e86820.

23. D'Adamo S, Cetrullo S, Guidotti S, Borzi RM, Flamigni F. Hydroxytyrosol modulates the levels of microRNA-9 and its target sirtuin-1 thereby counteracting oxidative stress-induced chondrocyte death. Osteoarthr Cartil. 2017;25(4):600-10.

24. Cheleschi S, De Palma A, Pascarelli NA, Giordano N, Galeazzi M, Tenti S, Fioravanti A. Could Oxidative Stress Regulate the Expression of MicroRNA$146 a$ and MicroRNA-34a in Human Osteoarthritic Chondrocyte Cultures? Int J Mol Sci. 2017;18(12).

25. Sun J, Zhong N, Li Q, Min Z, Zhao W, Sun Q, Tian L, Yu H, Shi Q, Zhang F, et al. MicroRNAs of rat articular cartilage at different developmental stages identified by Solexa sequencing. Osteoarthr Cartil. 2011;19(10):1237-45.

26. Zhong N, Sun J, Min Z, Zhao W, Zhang R, Wang W, Tian J, Tian L, Ma J, Li D, et al. MicroRNA-337 is associated with chondrogenesis through regulating TGFBR2 expression. Osteoarthr Cartil. 2012;20(6):593-602.

27. Gabler J, Ruetze M, Kynast KL, Grossner T, Diederichs S, Richter W. Stagespecific miRs in chondrocyte maturation: differentiation-dependent and hypertrophy-related miR clusters and the miR-181 family. Tissue Eng A. 2015;21(23-24):2840-51.

28. Sumiyoshi K, Kubota S, Ohgawara T, Kawata K, Abd El Kader T, Nishida T, Ikeda N, Shimo T, Yamashiro T, Takigawa M. Novel role of miR-181a in cartilage metabolism. J Cell Biochem. 2013;114(9):2094-100.

29. Xu J, Jiang C, Zhu W, Wang B, Yan J, Min Z, Geng M, Han Y, Ning Q, Zhang $F$, et al. NOD2 pathway via RIPK2 and TBK1 is involved in the aberrant catabolism induced by T-2 toxin in chondrocytes. Osteoarthr Cartil. 2015; 23(9):1575-85

30. Wu XF, Zhou ZH, Zou J. MicroRNA-181 inhibits proliferation and promotes apoptosis of chondrocytes in osteoarthritis by targeting PTEN. Biochem Cell Biol. 2017;95(3):437-44.
31. Latreche L, Jean-Jean O, Driscoll DM, Chavatte L. Novel structural determinants in human SECIS elements modulate the translational recoding of UGA as selenocysteine. Nucleic Acids Res. 2009;37(17):5868-80.

32. Touat-Hamici Z, Legrain Y, Bulteau AL, Chavatte L. Selective up-regulation of human selenoproteins in response to oxidative stress. J Biol Chem. 2014; 289(21):14750-61

33. Loeser RF, Carlson CS, Del Carlo M, Cole A. Detection of nitrotyrosine in aging and osteoarthritic cartilage: correlation of oxidative damage with the presence of interleukin-1 beta and with chondrocyte resistance to insulinlike growth factor 1. Arthritis Rheum. 2002;46(9):2349-57.

34. Min Z, Zhao W, Zhong N, Guo Y, Sun M, Wang Q, Zhang R, Yan J, Tian L, Zhang $F$, et al. Abnormality of epiphyseal plate induced by selenium deficiency diet in two generation DA rats. APMIS. 2015;123(8):697-705.

35. Papp LV, Lu J, Bolderson E, Boucher D, Singh R, Holmgren A, Khanna KK. SECIS-binding protein 2 promotes cell survival by protecting against oxidative stress. Antioxid Redox Signal. 2010;12(7):797-808.

36. Schoenmakers E, Agostini M, Mitchell C, Schoenmakers N, Papp L, Rajanayagam O, Padidela R, Ceron-Gutierrez L, Doffinger R, Prevosto C, et al. Mutations in the selenocysteine insertion sequence-binding protein 2 gene lead to a multisystem selenoprotein deficiency disorder in humans. J Clin Invest. 2010;120(12):4220-35.

37. Saito Y, Shichiri M, Hamajima T, Ishida N, Mita Y, Nakao S, Hagihara Y, Yoshida Y, Takahashi K, Niki E, et al. Enhancement of lipid peroxidation and its amelioration by vitamin $\mathrm{E}$ in a subject with mutations in the SBP2 gene. J Lipid Res. 2015;56(11):2172-82.
Ready to submit your research? Choose BMC and benefit from:

- fast, convenient online submission

- thorough peer review by experienced researchers in your field

- rapid publication on acceptance

- support for research data, including large and complex data types

- gold Open Access which fosters wider collaboration and increased citations

- maximum visibility for your research: over $100 \mathrm{M}$ website views per year

At BMC, research is always in progress.

Learn more biomedcentral.com/submissions 